\title{
Analysis on Contemporary Chinese Animated Music Development from Jou Hisaishi Animated Music
}

\author{
Chao Guo \\ School of humanities, Fujian Jiangxia University, Fuzhou, 350108, China
}

Key Words: Animated Music, Nationalization, Development

\begin{abstract}
In the development process of animation, lots of excellent animation works and music works spring up. Among these works, people especially take delight in talking about the combination of Jou Hisaishi and Miyazaki Hayao which has presented a high level for no matter the animation works or the music works. It is exactly such kind of creation which abandons commercialized keynote and starts with original innocence and nicety that gives full play to the thought and profundity of animation creators and musicians. By elaborating the success of Jou Hisaishi's animation music, the writer triggers deep thoughts of contemporary Chinese animated music development. In addition, the writer also puts forward that nationalization and diversification should be taken as essentiality to constantly explore the ideological level so that Chinese animated music art can be better developed.
\end{abstract}

In 1907, an American called Bracton created a short film The Humorous Phases of Funny Faces, marking the beginning of American animation history. In 1916, Japanese animation founders namely Shimokawa Oten, Junichi Kouchi and Seitaro Kitayama created series of animation named as Is Not It Wonderful which was widely welcomed. In 1926, China produced its first animation named as Studio Scene, unfolding the first page of Chinese animation history. Since the beginning of last century, animation has gradually come into people's sight and brought new interest to people especially children in the world. It creates an unrestrained magic world with unique technique and exaggerated manifestation mode. During the period when science fiction effect is not popularized and developed, animation is able to fully present people's imagination, emotion and scene which can not be expressed by real people. Even though most animation works in those days were dominated by silent ones, people's love for animation was not affected.

When attracted by the charming and magnificent frame and cliff-hanging plot in animation, people at the same time have a deep impression on its music and background. These animation images in screen along with all kinds of theme music have been integrated into one unit. As the times progress, technologies of making animation gradually become advanced. However, this does not become the principle element of the flourishing animation development in various countries. When Chinese animation is still confined to audiences of younger age and American animation goes too far to advocate individualistic heroism, Japanese animation chooses to serve people of all ages and has won more and more favor and attention with profound meanings. Japan finally becomes a country with large animation industry, the animated music production becomes more perfect, and the popularization becomes even more systematic. High-quality music works which were much-talked-about appeared during this period. These works, no matter placed in animation to match the plots and set off the animation theme and character role or separated out to be independently enjoyed from pure music perspective, can all be regarded as excellent music works and perfectly embody their own value.

In animation industry development, there are not so many people who are able to make high-quality animated music works until now. According to some people's traditional view, music which always serves for animation plots merely needs appearance in fixed animation scenes rather than so much conception and depth of melody. However, many preeminent musicians have abandoned this idea and in turn take music creation as demanding and high-quality input. The most outstanding one is Jou Hisaishi, the chief animated music master of animator Miyazaki Hayao who has experienced the glorious 20 years of Japanese animation history. Jou Hisaishi's music has 
become excellent music works which are not confined to just the animated movies for the reason that Miyazaki Hayao's animation works have great influences in Japan and even the whole world, and the works' level has risen up to the level of expressing humanism with help of their thoughts which have surpassed general animation works. Although like all the animated music, Jou Hisaishi's creation is based on the animation itself and takes the background generated to highlight characters' feature and animation as its original intention. People who have or have not seen Miyazaki Hayao's animation can feel unique meaning from Jou Hisaishi's music. As for those who have seen Miyazaki Hayao's animation, they can immediately remember Jou Hisaishi's music. No matter how long it has been, the sad or romantic or impressive plots in animation may emerge in their mind when the familiar melody rises again. As for those who have not seen Miyazaki Hayao's animation, they may construct some pictures in their mind when listening to Jou Hisaishi's music melody. The emergence of Jou Hisaishi music makes animated music no longer the assist of manifesting animation or making up for the blanks of silent days but expression of promoting animation plots.

Why is the combination of Miyazaki Hayao and Jou Hisaishi considered as a huge shock to the whole world? Jou Hisaishi's music can exquisitely grasp the meaning Miyazaki Hayao's animation wants to present. In addition, the most important reason is their mild and generous hearts and pure artistic spirit in cooperation. Miyazaki Hayao's animation works can be grouped into two types. One is to present relatively more profound themes. For example, Warriors of the Wind appeals for environmental protection as well as the coexistence and harmonious development of human and nature; Castle in the Sky presents how people satisfy their desire by destroying past dreams. The other is to express natural, pure and beautiful things. For example, My Neighbor Totoro praises children's innocence and goodness; The Borrower Arrietty describes the wonderful feeling between a child and "mini-girl”; From Up on Poppy Hill and Whisper of the Heart introduce the ignorant and young love of boys and girls. No matter the theme of Miyazaki Hayao animation is profound or not, there is no sad ending. His works are soft and full of people's pursuit of life and beautiful things, abandoning material, benefit, racial tension, etc. Those problems which seem irreconcilable in real life can all be readily solved in his animation. It seems as if everything in the world can find a perfect and peaceful ending. He advocates peace and appeals to pay more attention to tiny beautiful things around us; he loves nature and children's pure and unworldly heart. It is exactly his own beautifulness that deeply attracts all the people who watch his animated movie.

Nowadays, animated music is not confined to the background music in animated movie. Japanese manga works emerge in endlessly and are made into animation works which are broadcasted in various television media in form of serial. Therefore, the opening song, ending song, character theme song, and all kinds of background song are all the components of animated music. The diversified constitution makes that the appearance of an animation naturally drives lots of music producers and singers. The turning up of animated music has immeasurable effects on various musical and cultural fields at present. In each animation of Miyazaki Hayao, Jou Hisaishi's music is able to appropriately express different emotions at different stages. It makes the characters in animation alive and full of symbolization. In addition, it also makes the moving feeling which infects people's heart even more lively. Taking the theme music of Castle in the Sky as an example, violoncello is used to render the work's thick, solid and natural sense, and piano and flute are allocated as antithesis. As the frames gradually become bright and clear, the keynote of music turns to vigorous and energetic. Concerning the beautiful and kind-hearted friendship of major characters and the praise of children's pure and clinging belief, Jou Hisaishi;s music plays a rather appropriate role in serving as a foil to plot and theme. The cooperation of orchestra and children's chorus better presents a magnificent and ethereal picture, making the whole work and music blend with each other and form a complete unit. The music with very specific topicality and representativeness can perfectly lead audiences into the characters and movie contents, and can be easily remembered by them.

By contrast, Chinese animation industry at present does not have many animation characters which can be remembered by people, let alone animated movies which can be regarded as classic 
and complete animated music works. However, lots of people are still striving to develop Chinese animation and music up to a higher level. First of all, it is not how to add making technology and painting style but to improve the height of animation works and music works. The wrong idea in traditional views that animation is merely for children should be changed; the misunderstanding that animated music is just the assist of animation should also be timely corrected. Even though what we have discussed are all the examples how Jou Hisaishi makes Miyazaki Hayao success, it does not show that their cooperation is collision by accident and there is no other successful cases. Disney and Ghibli Studio have existed for decades. They are all the way favored by children and even adults in the world definitely not just because of their preeminent technological means and expensive capital investment. Disney and DreamWorks are not confined to merely animation field nowadays but turn to movie aspect. They perfectly integrate animation and reality, satisfying American higher and more delicate commercialized development. However, Ghibli Studio still keeps reminiscence style, which may be related with Miyazaki Hayao's idea. Nevertheless, excellent animation and music can be remembered as well no matter for tending to commercialized development or pursuing desire in the innermost recesses of heart, because the more national it is, the more international it is. How to better carry forward music with Chinese cultural characteristics is the significant method and way of preferably receiving social recognition. The music of Mickey and Donald animation created by early Disney and Shrek created by DreamWorks is full of American passion and European flavour of fairy tale, while the works created by Miyazaki Hayao's Ghibli Studio are full of memory of people in the 1930s and 1940s. No matter he describes the scenery of which country; the works all overflow a plain, romantic and tranquil culture. Especially the freshness and grace in Showa years are the favorite of Miyazaki Hayao. Moreover, the success of Kung Fu Panda skillfully applies national elements like Chinese Paper Cutting. There is a strong "Chinese Style" embodiment in the background music. Western electronic music and orchestral music and Chinese traditional Beijing opera drumbeat are perfectly combined with each other. National instrument such as bamboo flute, dulcimer, pipa, etc unfold the melody of Chinese pentatonic mode along with plots, which to some extent names the movie theme very well. At the same time, it obtains very good economic benefit in commercialization process. Thus it can be seen that Chinese animation and music should get out of the misunderstanding of blindly worshiping everything foreign, take successful animation cases of various countries as reference, and come back to the essence.

After imitating and taking European, American and Japanese animation development modes as reference, China gradually has its own original animated music and animated songs. For example, there are three theme songs in Lotus Lantern which are sung by three famous singers respectively from mainland, Hong Kong and Taiwan. Different styles together show a same "Love" theme. Animation sitcom named as Music Up is a Chinese animation work widely welcomed by youngster. Its song-oriented soundtrack album is also favored and accepted by contemporary people. Nevertheless, the animated music creation level of Europe, America and Japan is still so much higher than that of China. That is to say the essence lies not merely in imitation. At present, Chinese animation and music fail to achieve the goals they have set. Even though China in five thousand years has so many stories to describe or to praise, and China's traditional virtue and fairy stories are not less than that of other countries, its making technology compared with other countries still has a certain distance to go. For example, Qin's Moon has realized that the whole voluminous animation is presented in form of $3 \mathrm{D}$, and the character portraying is becoming more and more exquisite. However, it still seems that something quintessential is missing. The audiences of movie Pleasant Goat and Big Big Wolf are mainly young children as before. It naturally pays less attention to the background music design in movie, which may because of an objective factor that there are so many development restrictions for Chinese animation. The reason can also be the fact that plenty of excellent creators do not attach importance to and fully explore animation market. As for no matter plot creation or music creation, China seems achieve no impressive goals in animation field. What carries music is not merely animation itself. Except for watching movies, people can listen to the song-oriented soundtrack album of animated movies through various resources. In recent years, 
there are lots of examples which popularize original music through the success of animated movies. Similarly, the public group may start to concern animated movies for loving the original animation music or theme music. It is the goal for every musician, who has spent so much energy and so many years in seeking for it, to achieving greater success for carrier with music as media, to better arouse the public resonance and to make the central meaning and main idea more concrete for understanding. Therefore, how to better perfect their own music thinking and knowledge, how to start from the essence and how to resist the superficial temptation of commercialization are the future which contemporary musicians should think about and strive for. Only in this way can they create really excellent works which are rich in connotation and can be handed down as classic.

The collision of music and animation is not a spark by accident but an intense effect which can bring profound knowledge. Animation as a favorable carrier of music can bring broad creative space and unrestrained imagination to music. Music serves as a best foil to characters and plots in animation, perfectly combines fantasy and reality, and attracts people so much that they become deeply addicted. Animation art is a way to present people's longing at the bottom of heart for pure things and pursuit of beautiful emotion through common and concrete images. Such kind of pursuit for beauty in depths of human nature and the essence of art are interlinked. No matter for purpose of carrying forward nationalized elements, or exploiting diversified artistic creation domain or reaching a new height of the life value of individual creation, people need to keep trying and diligently go on in the way of pursuing artistic realm of higher level, creating new culture and new art with contemporary Chinese characteristics.

\section{References}

[1] Zheng Junyi. Analysis on the creative characteristics of Jou Hisaishi animated movie music works[J]. Musical Creation. 2010（01）

[2] Fan Liming. Yesterday, today and tomorrow of Chinese animation[J]. Journal of Thai Nguyen University. 2001 (03)

[3] Xiang Duo. Reflections on the development status of Chinese animated music[J].Journal of Jilin Provincial Institute of Education .2014（02）

[4] Cheng Xingwang. Chinese animated movie music at early stage and its historical status [J]. Journal of Central Conservatory of Music .2010 (02)

[5] Dai Yuhong, Luo Bin. Analysis on Chinese animation from animation development history[J]. Journal of Chengdu University(Social Science Edition). 2006（04） 